\title{
The Role of Liquidity Constraints in Fuelling The Demand-Pulled Innovation
}

\author{
Yeşim ÜÇDOĞRUK'
}

\section{ABSTRACT}

The motivation to classify industries in their effort to innovate with the structure of demand, lead to a theoretical controversy in innovative activity known as'demand-pull'versus'technology-push' forces of technical change. Previous empirical literature has provided evidence supporting demandpulled innovation both at the aggregate level and at the firm level. This paper studies a dynamic specification of the demand-pull hypothesis at the firm level, which takes into account both the within and the between effects across Turkish non-financial firms listed at Istanbul Stock Exchange (ISE) over a period of ten years (1998-2007). Moreover, the study also investigates the demand-innovation relationship in liquidity constrained firms since inducing an increase in the effort to innovate mostly depends on the funding of expensive and uncertain R\&D activities. Our findings confirm the demand-pull hypothesis, yet the role of sales in inducing R\&D expenditures is $99 \%$ significant in the overall sample. More specifically, liquidity constrained firms and firms not receiving public subsidies seem to be particularly sensitive to sales when deciding how much to spend on R\&D.

Key Words: R\&D expenditures, demand-pulled innovation, LSDVC estimator.

\section{INTRODUCTION}

The motivation to classify industries in their effort to innovate with the structure of demand, lead to a theoretical controversy in innovative activity known as 'demand-pull' versus 'technology-push' forces of technical change. 'Demand-pull' influences in innovative activity include effects driven by changes in consumer demand, the competitive structure of markets and factors affecting the valuation and appropriability of innovations. In the Schumpeterian tradition, increasing sales induce an increase in the effort to innovate by allowing the funding of expensive and uncertain research and development (R\&D) activities, while at the same time the appropriability of the returns from innovative activity rise with market size (Schumpeter, 1942). From an empirical point of view, Schmookler (1966) was the first author to test the demand-pull hypothesis at the sectoral level. In his debated work, Schmookler argued that the main stimulus to innovation came from the changing pattern of demand as measured by the investment in new capital goods in various industries. Schmookler found that firms in "science-based industries" produced much more innovation for a given amount of sales than firms in other sectors and underlined the importance of different technological regimes that characterize the different industrial sectors. Later on, Scherer (1982) tested the demand-pull hypothesis together with the sectoral peculiarities in innovation by using technology-class dummies. His results confirmed the correlation between patenting and in- vestment and suggested that differences in technological opportunities must be taken into account for demand-pull stimuli.

As far as econometric studies are concerned, empirical literature has provided further evidence supporting demandpulled innovation both at the aggregate level (entire economy and industrial sectors, see Geroski and Walters, 1995; Kleinknecht and Verspagen, 1990) and at the microeconomic (firm) level (see, Brouwer and Kleinknecht, 1999; Cainelli et. al., 2006; Crepon et. al., 1998; Piva and Vivarelli, 2007; 2009; Scherer, 1982) by using different innovation indicators such as patent statistics and R\&D expenditures.

Previous studies seem to be affected by some limitations that are surveyed in Piva and Vivarelli (2007). First, most of these studies use cross-section analyses that focus mainly on the between differentials. Availability of panel data wipes out possible firm specific fixed effects and deal with endogeneity problems associated with simultaneous occurrence of innovation and increasing sales within the firms. Examining the relationship between demand and innovation for Dutch manufacturing industry, Kleinknecht and Verspagen (1990) were the first that pointed out this endogeneity problem and underlined that there is a lag between innovation and final patenting. Geroski and Walters (1995) pointed out this endogeneity problem between demand and innovation at the macroeconomic level for the UK. They found significant evidence that variations in economic activity (proxied by an 
index of GDP at current factor cost) do cause changes in innovative activity but no evidence of the reverse effect.

The other limitation of previous studies depends on lack of micro-econometric evidence at the level of firm. Recent studies have focused on firm level data that has advantage over aggregate level by measuring innovation activity better. Some examples are Brouwer and Kleinknecht (1999) for Dutch firms, Crepon et. al. (1998) for French firms and Cainelli et. al. (2006) for Italian service firms. Using Community Innovation Survey (CIS) data, these studies take a step further in testing the demand-pull hypothesis by taking into account the strong path-dependence of innovative activity through different technological opportunities and presence of fixed effects related to firm specific capabilities.

While the above mentioned micro-econometric studies control for technological opportunities and fixed effects at the firm level, they lack a continuous time dimensions in the datasets used. So, most of these studies can not propose a dynamic specification of the demand-pull hypothesis at the firm level. In this respect, although the paper by Hall et. al. (1999) is based on investigating the causal relationship among sales and investment inputs (both tangible and intangible) for French, Japanese and US high-tech firms, they found that sales growth led to R\&D growth in all countries by controlling for the lagged values of R\&D and sales. More recently, using a dynamic specification in determining the scope of demand-pull effect, Piva and Vivarelli (2007) found that $R \& D$ investment is positively responsive to sales both in the short-run and long-run for Italian manufacturing firms for 1995-2000.

By the same token, previous micro-econometric evidence at the firm level did not distinguish between different groups of firms characterized by particular features that are important in determining the scope of the demand-pull effect. The finding of Hall et. al. (1999) that R\&D in US firms appears to be more sensitive to past sales and cash flow than their French and Japanese counterparts, suggests another improvement in the analysis of demand-pull hypothesis. This is an important suggestion of the possible role of liquidity constraints that can make the demand-pull impact more of less effective since sales and cash flow might be more crucial in inducing and funding R\&D for firms having difficulties in raising credit. There is only one study by Piva and Vivarelli (2009) that examines whether demand-pulled innovation is important for liquidity constrained firms. They found a significant confirmation of the demand-pull innovation for the liquidity constrained Italian manufacturing firms for 1995-2001.

This paper studies a dynamic specification of the demandpull hypothesis at the firm level, which takes into account both within and between effects across Turkish non-financial firms listed at Istanbul Stock Exchange (ISE) over a period of ten years (1998-2007). First, the demand-pull hypothesis is tested using all of the firms that constitute the dataset. Taking for granted the significant effect of the lagged R\&D variable along a firm's specific technological trajectory, we examined whether increasing demand has a role in inducing higher R\&D investment both in the short and long run. Moreover, the study also analyzes possible role of demandpulled innovation for liquidity constrained firms. The aggregate and sub-group estimates are run using Ordinary Least Square (OLS), Least Squares Dummy Variable (LSDV) and LSDVC estimates (corrected estimator LSDV that is a recently proposed panel data technique suitable for small samples).

The novelty of this paper is to investigate the demandpull hypothesis at the firm level using a panel dataset. The role of liquidity constraint and public support in this process will also be analyzed. Another novelty of this paper is to take a first step towards filling a gap on the demand-innovation relationship for publicly traded firms in Turkey. Moreover, as manufacturing firms constitute a substantial share (85\%) of ISE listed firms, the panel dataset of non-financial ISE firms provides a fruitful experiment in analyzing the market valuation of R\&D investment through the scope of demand-pull effect by the stock markets.

The paper consists of four sections. The second section presents the data sources and provides a descriptive analysis on the characteristics of R\&D performers by firm size (large vs. small), public support recipient status and liquidity constraint. Section three discusses the methodological issues and the fourth section presents the hypothesis to be tested and findings of an econometric analysis regarding the role of sales in inducing R\&D. The role of demand-pull effect for liquidity constrained firms is also analyzed in this context. The last section of the paper summarizes main findings and discusses policy implications.

\section{DATA SOURCES}

There are two basic data sources used in this study. The corporate-level accounting and performance information was from the ISE Financial Statements. It is an electronic database that provides information on the corporate performance and other financial indicators of all ISE listed firms. Additionally, data on the international activities of firm, its location and age is collected from ISE Company Yearbook providing information on to supplement the information from ISE Financial Statements. We ended up with a panel of 225 non-financial firms covering the manufacturing and service sectors over a ten-year period. The main constraint in the study of testing demand-pull hypothesis is the lack of suitable databases aimed at measuring the link between sales and $R \& D$ investment as well as R\&D investment enhancing 
measures like R\&D support and investment incentives over a time-series dimension. In this regard, although the ISE listed firms are to be biased for large firms and the data set is not very large, this is a reliable dataset providing a beneficial experiment as far as the lack of comparable data for all firms in Turkey is concerned.

In line with Piva and Vivarelli (2007) and (2009), we measure innovation using the value of R\&D expenditures declared by firms while demand is measured by sales. Selecting R\&D expenditures as a proxy for innovation has some drawbacks. One of them is that, R\&D data has always a limited capability as an innovation indicator by the fact that it measures input only (see Piva and Vivarelli, 2007). The fact that $R \& D$ is an input indicator suits for the proper investigation of demand-pull hypothesis as we should avoid the endogeneity problem arising due to possible feedback between innovation outputs and sales. The second drawback rests on the fact that R\&D data underestimates innovation within small firms since they undertake innovation mainly through external technology acquisition (Kleinknecht et. al., 2002). However, our dataset is made up of medium and large firms where innovation is formalized in R\&D investment. Moreover, the only time-variant information provided in ISE Financial Statements is the R\&D expenditure data available quantitatively through 10 years.

Table 1: Number of non-financial firms listed at ISE (1998-2007)

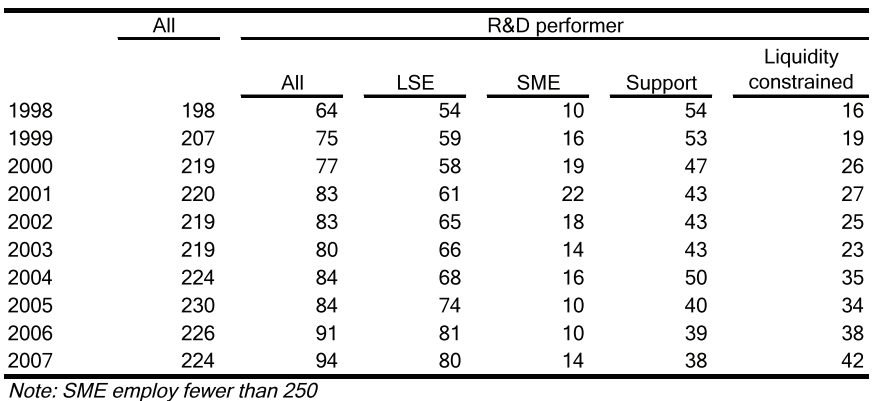

Source: ISE Financial Statements.

Table 1 presents the data on the number of firms in the database presented for all firms and R\&D performer firms that are defined by size 1 (LSE vs. SME), being public support recipient and liquidity constrained. A firm is defined as a public support recipient if it received any public support in the form of R\&D grants or investment allowances. R\&D and investment support recipients are merged together since their number is quite few especially in SMEs. Additionally, liquidity constrained firms are the ones that have a ratio of current assets to current liabilities exceeding the mean value. The share of R\&D performers continued to increase from $32 \%$ in 1998 to $42 \%$ in 2007. The share of R\&D performers has slowed down after the 2001 crisis and their share remained unchanged (37\%) somewhat until 2005. Among three categories of firms, large firms are more likely to conduct $R \& D$ (on average, $82 \%)$. On the other hand, small firms (18\%) are less likely to be involved in R\&D activities. The share of support recipient firms that perform $R \& D$ is close to $56 \%$. However, the share of support recipients decreased from $84 \%$ in 1998 to $40 \%$ in 2007. This decrease in the number of support recipients is the result of changes in the provision of investment incentives by the government over time. The share of liquidity constrained firms that conduct R\&D is $34 \%$ on average. This share has increased from $25 \%$ in 1998 to $45 \%$ in 2007. Thus, R\&D performer ISE firms face with financial difficulties over the period 1998-2007.

Figure 1: Sales growth rate (\%) (1998-2007)

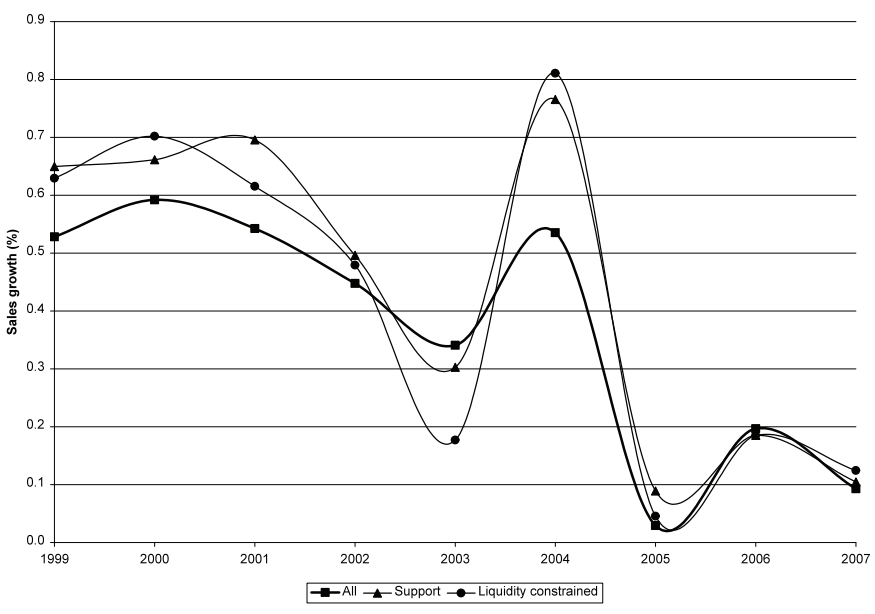

Source: ISE Financial Statements.

Figure 1 presents annual sales growth rate of R\&D performers for the period 1998-2007 for all of, the public support recipient and the liquidity constrained firms, respectively. The sales growth rate has slowed down in 2001 crisis for all categories of the firms but the growth rate of sales was hit the hardest in 2005. After 2002, the growth rate of sales followed a cyclical movement of one year recovery and one year deterioration. For the period 2002-2006, the sales growth rate for all categories of firms decline reaching half of the value they were in 2002. For all categories of firms, the sales growth of support recipient firms is the highest (on average, 44\%) except 2004 and 2007. In 2004, the sales growth of liquidity constrained firms reached to the highest value of all years (81\%).

Similarly, Figure 2 presents annual growth rate of R\&D expenditure for the period 1998-2007 for all, public support recipient and liquidity constrained firms respectively. The same deduction holds for the growth rate of R\&D expenditures for all categories of firms. For all categories of firms, the sales growth of liquidity constrained firms is the highest (on 
average, 54\%) except 2005. In 2005, the sales growth of liquidity constrained firms reached to the lowest value of all years (8\%).

Figure 2: R\&D expenditure growth rate (\%) (1998-2007)

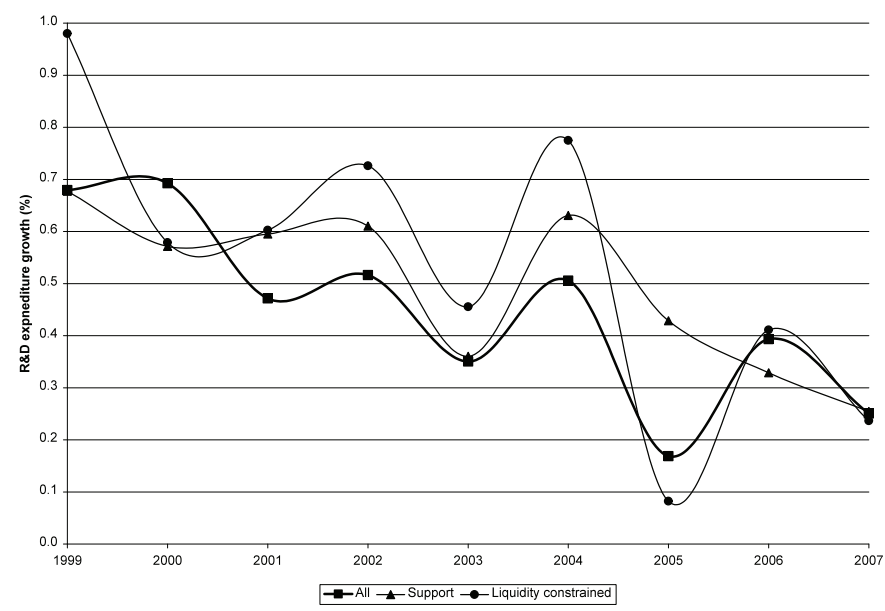

Source: ISE Financial Statements.

\section{METHODOLOGY}

The descriptive analysis presented in the preceding section showed that there are substantial differences between R\&D activities of large and small firms, support recipient and liquidity constrained firms. We will analyze the role of sales in stimulating R\&D activities for non-financial firms listed at ISE by using econometric methods to understand if support receiving and liquidity constraints has a role in the demandpull effect.

The model used for testing the demand-pull hypothesis both for aggregate and the liquidity constrained firms have the following specification for firms (i) over time $(\mathrm{t})$ :

$\mathrm{RD}_{\mathrm{i}, \mathrm{t}}=\alpha \mathrm{RD}_{\mathrm{i}, \mathrm{t}-1}+\beta_{1}$ sales $_{\mathrm{i}, \mathrm{t}}+\beta_{2}$ sales $_{\mathrm{i}, \mathrm{t}-1}+\left(\eta_{\mathrm{i}}+v_{\mathrm{i}, \mathrm{t}}\right) \mathrm{i}=1, \ldots, \mathrm{N}: \mathrm{t}=1, \ldots, \mathrm{T}$

(1) where variables are expressed in natural logarithms, $E$ is the idiosyncratic individual and time-invariant firm's fixed effect and $\Sigma$ is the usual error term. In addition, a full set of time and sectoral ${ }^{2}$ dummies has been introduced into the analysis.

The reason for including the lagged $R \& D$ expenditures into our model is the path-dependence and cumulative nature of innovative activity. So, any model analyzing the present R\&D investment necessarily involves considering the previous R\&D investment along a 'technological-trajectory'. Moreover, current and lagged values of sales have to be included in the model in order to test demand-pull hypothesis. The inclusion of lagged value of sales may cause an endogeneity problem as discussed previously. Our dependent vari- able, R\&D expenditure, measures initial investment in $R \& D$ prior to innovation. Since R\&D expenditures have an uncertain and delayed outcome in terms of subsequent innovation, the possible reverse effect is between future successful innovation and future sales (Piva and Vivarelli, 2007: 697).

The above model testing the relationship between demand and innovation is defined as a dynamic equation by including the lagged value of the $R \& D$ expenditure in order to account for the adjustment and persistence in R\&D activities. The inclusion of lagged dependent variable leads to another endogeneity problem that can be solved by firstorder dynamic panel data models that use General Method of Moments (GMM; see Arellano and Bond, 1991; Arellano and Bover, 1995; Blundell and Bond, 1998). However, a weakness of GMM estimators is that their properties hold when $\mathrm{N}$ is very large, so they can be severely biased and imprecise in panel data with a small number of cross-sectional units (Bruno, 2005b). Hence, this method is not suitable for small samples like the ones used in our analysis since we select a sub-sample of firms from the original panel to test the demand-pull effect under different firm characteristics. Therefore, we used an alternative method based upon the bias correction of least-squares dummy variable (LSDV) estimator in dynamic panel data models proposed by Kiviet (1995), Bun and Kiviet (2003) and extended by Bruno (2005a).

Moving from a standard autoregressive panel data model, based on the possibility of collecting observations over time and across individuals; our problem can then be described as follows:

$\mathrm{y}=\mathrm{D} \eta+\mathrm{W} \delta+v$

(2) where $y$ is the vector of observations for the dependent variable, $D$ is the matrix of individual dummies, $E$ is the vector of individual effects, $W$ is the matrix of explanatory variables including lagged dependent variable, $J$ is the vector of coefficients and $\Sigma$ the usual error term. The Least Squares Dummy Variable (LSDV) estimator is given by:

$\delta_{\text {LSDV }}=\left(\mathrm{W}^{\prime} \mathrm{AW}\right)^{-1} \mathrm{~W}^{\prime} \mathrm{Ay}$

(3) where $A$ is the within transformation that wipes out the individual effects (means). Since the LSDV estimator is not consistent, a more accurate measuring of its bias is needed to correct it. The LSDV bias is given by:

$\mathrm{E}\left(\delta_{\mathrm{LSDV}}-\delta\right)=\mathrm{C}_{1}\left(\mathrm{~T}^{-1}\right)+\mathrm{c}_{2}\left(\mathrm{~N}^{-1} \mathrm{~T}^{-1}\right)+\mathrm{C}_{3}\left(\mathrm{~N}^{-1} \mathrm{~T}^{-2}\right)+\mathrm{O}\left(\mathrm{N}^{-2} \mathrm{~T}^{-2}\right)$

(4) In their Monte Carlo simulations, Bun and Kiviet (2003) and Bruno (2005) consider three possible nested approximations of the LSDV bias. With an increasing level of accuracy, the following three possible bias approximations emerge:

$B_{1}=\mathrm{c}_{1}\left(\mathrm{~T}^{-1}\right) ; B_{2}=B_{1}+\mathrm{c}_{2}\left(\mathrm{~N}^{-1} \mathrm{~T}^{-1}\right) ; B_{3}=B_{2}+\mathrm{c}_{3}\left(\mathrm{~N}^{-1} \mathrm{~T}^{-2}\right)$ 
(5) In this study, using the third one as the correction, the LSDV corrected estimator (LSDVC) will be equal to

LSDVC $=$ LSDV $-B_{3}$

(6) The Monte Carlo experiments (see Bruno, 2005a) show that the LSDVC estimator, in small samples, outperforms consistent IV-GMM estimators such as the Anderson-Hsiao and Arellano-Bond. The procedure has to be initialized by a consistent estimator to make the correction feasible, since the bias approximation depends on the unknown population parameters. Three possible options for this purpose are the Anderson-Hsiao, Arellano Bond and Blundell-Bond estimators that are asymptotically equivalent. In this study, we will initialize the bias correction with the Arellano-Bond estimator, here considered as the best established panel data estimator implemented in the STATA econometric package used3. Moreover, the statistical significance of the LSDVC coefficients has been tested using bootstrapped standard errors (100 iterations) because the estimated asymptotic standard errors may provide poor approximations in small samples, generating possibly unreliable t-statistics (Bruno, 2005b).

\section{THE ROLE OF DEMAND-PULLED INNOVATI- ON FOR LIQUIDITY CONSTRAINED FIRMS: ESTI- MATION RESULTS}

We will first start by testing the demand-pull hypothesis using all of the firms that constitute the dataset. Taking for granted the significant effect of the lagged $R \& D$ variable along a firm's specific technological trajectory, we will analyze whether increasing demand has a role in inducing higher R\&D investment both in the short and long run. Moreover, the rest of the analysis will be devoted to check for the role of demand-pulled innovation for liquidity constrained firms. In line with the issues discussed in the literature, we will first test whether liquidity constraints constitute a more significant stimulus to innovation. As suggested by Hall et. al. (1999), firms affected by liquidity constraints should be more dependent on internal cash flow and so should be more sensitive to current sales when deciding to engage in R\&D investment. By the same token, firms benefiting from public subsidy should be less sensitive to current sales, since they have an alternative source of funding to devote to R\&D investment (David et. al., 2000).

The following tables (Table 2-4) present the results of the aggregate and sub-group estimates that are run by using Ordinary Least Square (OLS), Least Squares Dummy Variable (LSDV) and LSDVC outcomes. In both tables, both OLS and LSDV estimates exhibit a satisfactory fit (see $\mathrm{R}^{2}$ and $\mathrm{F}$ tests), although reliable results are provided only by the third estimates, applied by the Arellano-Bond estimator to get accu- racy of approximation of bias $B_{3}$ and characterized by bootstrapped standard errors. Hence, comments will be based only on LSDVC estimates, considering both the short-term impact of current sales and the long-term effect combining the impacts of both current and lagged sales. All the estimates are checked both for time (in order to take into account possible aggregate and cyclical effects) and sectoral dummies.

When we look at the estimates reported in all of the tables, they are affected by strong path dependence in R\&D expenditures; the coefficient of the lagged dependent variable is always significant at the $99 \%$ degree of confidence with a value ranging from a minimum of 0.32 to a maximum of 0.64 . This almost uniform and highly significant outcome can be interpreted as further confirmation of the presence of cumulative technological trajectories at the level of the single firm.

Returning our attention first to the aggregate estimates reported in Table 2, we found a significant confirmation of the demand-pull hypothesis: R\&D investment is positively responsive to sales both in the short and long run4, with corresponding elasticities equal to 0.52 and 0.82 . On the whole, $R \& D$ expenditures are basically an $A R(1)$ process with the demand-pull effect playing a positive role. Together with suggestions from previous literature and with the hypotheses put forward in the first part of this section, this result needs a more detailed investigation which can be carried out by splitting our sample into sub-groups of firms according to liquidity constraints and public support status. In other words, this aggregate result, although consistent with previous literature, may not be very informative and may even conceal more obvious demand-pull effects within particular sub-samples of firms characterized by specific features.

Table 2: Demand-pulled innovation (1998-2007) OLS, LSDV and LSDVC estimation results

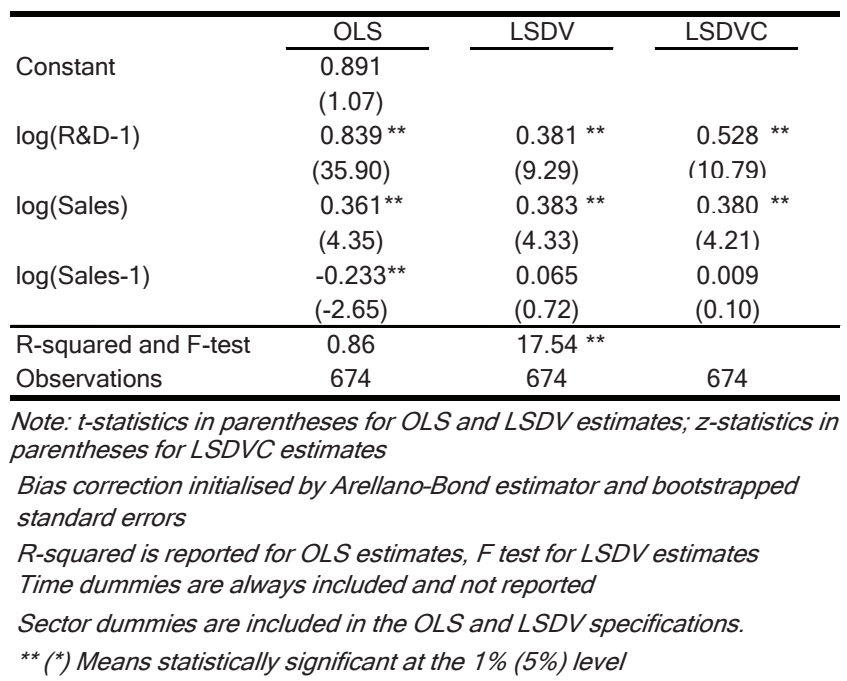


In order to control access to finance, affecting firm's ability to invest in R\&D, firm's "liquidity constraint" in terms of current ratio calculated by current assets over current liabilities is used in testing demand-pull hypothesis. As the average current ratio for the period 1998-2007 is 1.79, firms are divided into two groups depending on whether they are above or below the mean value. Sales and cash flow should be more crucial in inducing and financing $R \& D$ projects in liquidity constrained firms and in firms without any kind of public support from tax exemptions and/or subsidies. This seems to be the case in Tables 3 and 4, where firms affected by difficulties in raising credit and which are unsubsidized and hence financially constrained, are seen to be much more sensitive to sales. While the demand-pull hypothesis is significantly supported (99\%) by the two sub-samples made up of constrained firms, it emerges as statistically significant and positive, when using the two complementary sub-samples of firms with softer budget constraints owing to the availabi-

Table 3: Demand-pulled innovation, liquidity constraint (1998-2007) OLS, LSDV and LSDVC estimation results

\begin{tabular}{|c|c|c|c|c|c|c|}
\hline & \multicolumn{3}{|c|}{ Liquidity constraint (yes) } & \multicolumn{3}{|c|}{ Liquidity constraint (no) } \\
\hline & OLS & LSDV & LSDVC & OLS & LSDV & LSDVC \\
\hline \multirow[t]{2}{*}{ Constant } & $\overline{1.661}$ & & & -0.220 & & \\
\hline & $(2.11) *$ & & & $(-0.32)$ & & \\
\hline \multirow[t]{2}{*}{$\log (R \& D-1)$} & 0.860 ** & 0.511 ** & 0.643 ** & 0.815 ** & 0.224 ** & 0.325 ** \\
\hline & $(30.10)$ & $(10.18)$ & $(8.35)$ & $(18.91)$ & $(2.72)$ & $(3.16)$ \\
\hline \multirow[t]{2}{*}{$\log ($ Sales) } & 0.431 ** & 0.562 ** & 0.558 ** & 0.136 & 0.309 & 0.283 \\
\hline & $(4.81)$ & $(5.60)$ & $(4.64)$ & $(0.58)$ & $(1.08)$ & $(0.79)$ \\
\hline \multirow[t]{2}{*}{$\log ($ Sales-1) } & $-0.325 * *$ & -0.035 & -0.095 & 0.043 & 0.447 & 0.422 \\
\hline & $(-3.35)$ & $(-0.36)$ & $(-0.80)$ & $(0.17)$ & $(1.72)$ & $(0.96)$ \\
\hline $\mathrm{R}$-squared and F-test & 0.88 & $20.95^{* *}$ & & 0.87 & $4.55^{* *}$ & \\
\hline Observations & 417 & 417 & 417 & 230 & 230 & 230 \\
\hline
\end{tabular}

Note: $t$-statistics in parentheses for OLS and LSDV estimates; $z$-statistics in parentheses for LSDVC estimates Bias correction initialised by Arellano-Bond estimator and bootstrapped standard errors

$R$-squared is reported for OLS estimates, F test for LSDV estimates

Time dummies are always included and not reported

Sector dummies are included in the OLS and LSDV specifications.

${ }_{* *}^{*}\left({ }^{*}\right)$ Means statistically significant at the $1 \%(5 \%)$ level

Table 4: Demand-pulled innovation, public subsidy recipient (19982007) OLS, LSDV and LSDVC estimation results

\begin{tabular}{|c|c|c|c|c|c|c|}
\hline \multirow{4}{*}{ Constant } & \multicolumn{3}{|c|}{ Public subsidy (yes) } & \multicolumn{3}{|c|}{ Public subsidy (no) } \\
\hline & OLS & LSDV & LSDVC & OLS & LSDV & LSDVC \\
\hline & -1.472 ** & & & -0.545 & & \\
\hline & $(-2.69)$ & & & $(-0.84)$ & & \\
\hline \multirow[t]{2}{*}{$\log (R \& D-1)$} & $0.767^{* *}$ & 0.356 ** & 0.507 ** & $0.877^{* *}$ & $0.203^{* *}$ & 0.321 ** \\
\hline & $(21.08)$ & $(5.47)$ & $(4.53)$ & $(27.58)$ & (3.19) & $(2.62)$ \\
\hline \multirow[t]{2}{*}{$\log$ (Sales) } & 0.110 & 0.190 & 0.153 & 0.439 ** & $0.395^{* *}$ & 0.390 ** \\
\hline & $(0.61)$ & $(0.92)$ & $(0.61)$ & $(4.69)$ & $(4.31)$ & $(3.03)$ \\
\hline \multirow[t]{2}{*}{$\log$ (Sales-1) } & 0.100 & 0.473 * & 0.412 & $-0.356 * *$ & -0.002 & -0.036 \\
\hline & $(0.53)$ & $(2.32)$ & (1.43) & $(-3.57)$ & $(-0.02)$ & $(-0.20)$ \\
\hline R-squared and F-test & 0.86 & $7.74^{* *}$ & & 0.87 & $7.18^{* *}$ & \\
\hline Observations & 352 & 352 & 352 & 322 & 322 & 322 \\
\hline
\end{tabular}

Note: $t$-statistics in parentheses for OLS and LSDV estimates; $z$-statistics in parentheses for LSDVC estimates

Bias correction initialised by Arellano-Bond estimator and bootstrapped standard errors

$R$-squared is reported for OLS estimates, F test for LSDV estimates

Time dummies are always included and not reported

Sector dummies are included in the OLS and LSDV specifications.

** (*) Means statistically significant at the $1 \%(5 \%)$ level lity of external private or public money. Moreover, financially constrained and unsubsidized firms exhibit positive and larger long-term innovation elasticity to sales (1.11 and 0.52 , respectively). These results are consistent with the previous literature and support hypotheses that liquidity constrained firms should be more reactive to sales than firms that do not have any kind of difficulty in raising external funds and obtaining bank credit (for a similar finding, see Piva and Vivarelli, 2007 and 2009).

\section{CONCLUSION AND DISCUSSION}

As far as econometric studies are concerned, previous empirical literature has provided further evidence supporting demand-pulled innovation both at the aggregate and firm level that is first proposed and tested by Schmookler (1966). However, previous studies seem to be affected by some limitations such as firm-specific fixed effects, endogeneity problem associated with simultaneous occurrence of innovation and increasing sales, and lack of continuous time dimensions in the datasets used. Moreover, previous evidence at the firm level did not distinguish between different groups of firms characterized by particular features that are important in determining the scope of the demand-pull effect.

This paper puts forward a dynamic specification of the demandpull hypothesis at the firm level, which takes into account both within and between effects across Turkish non-financial firms listed at ISE over a period of ten years (19982007). Checking for firms' fixed effects and for the significant effect of the lagged R\&D investment along a firm's specific technological trajectory, the provided evidence does not reject the demand-pull hypothesis, yet the role of sales in inducing R\&D expenditures is $99 \%$ significant in the overall sample. In contrast, both the short-term and long-term impacts of demand become obvious and statistically significant for specific groups of firms. More specifically, liquidity constrained firms and firms not receiving public subsidies seem to be parti- 
cularly sensitive to sales when deciding how much to spend on R\&D.

Our analysis based on testing the demand-pull hypothesis provides a number of policy relevant findings. As far as macroeconomic scenarios are concerned, a first conclusion is that fluctuations in aggregate demand may not only have effects on production and employment, as emphasized by the Keynesian tradition, but may also have important consequences in terms of the innovative potential of a given economy, in accordance with the Kaldor-Verdoorn law (Piva and Vivarelli, 2007: 707). This means that proponents of fiscal and monetary policies should consider carefully the possible side effects in fostering or hampering innovation. However, our results call for further condition; policies aiming at increasing demand may be particularly important in encouraging innovative activity in liquidity constrained firms. This does suggest that as part of effective innovation policies, the impact of effective demand should always be an important criterion in the decision process about government policy measures.

In terms of policy implications, our results provide strong support for targeted industrial and innovation policies which should be able to encourage those firms that need a substantial increase in output in order to pursue R\&D investments. Moreover, these policies are essential to raise technological capabilities of firms that face with financial obstacles in R\&D investments, especially in developing countries like Turkey.

\section{END NOTES}

1. Establishments employing fewer than 250 people are classified as "small and medium-sized enterprise" (SME). Large-scale enterprises (LSE) employ 250 or more people.

2. Sector is defined at the ISIC (revision 2) 2-digit level.

3. For a further discussion on LSDVC estimator and the finite-sample performance of three bias corrections with different estimators (Anderson-Hsiao, Arellano-Bond and Blundell-Bond), see Bruno (2005b).

4. The 'long-run' elasticity takes into account the impact of both current and lagged sales according to the formula $\left(\beta_{1}+\beta_{2}\right) /(1-\alpha)$

\section{ACKNOWLEDGEMENTS}

The author is very grateful to two anonymous referees for their invaluable comments and suggestions. The usual disclaimer applies.

\section{REFERENCES}

Arellano, M. and Bond, S. (1991): "Some tests of specification for panel data: Monte Carlo evidence and an application to employment equations", Review of Economic Studies, 58: 277-297.

Arellano, M. and Bover, O. (1995): "Another look at the instrumental variables estimation of error components models", Journal of Econometrics, 68: 29-51.

Blundell, R. and Bond, S. (1998): "Initial conditions and moment restrictions in dynamic panel data models", Journal of Econometrics, 78(1): 115-143.

Bruno, G. (2005a): "Approximating the bias of the LSDV estimator for dynamic unbalanced panel data models", Economics Letters, 87: 361-366.

Bruno, G. (2005b): "Estimation and inference in dynamic unbalanced panel data models with a small number of individuals", The Stata Journal, 5(4): 473-500.

Brouwer, E. and Kleinknecht, A. (1999): "Keynes-plus? Effective demand and changes in firm-level R\&D: an empirical note", Cambridge Journal of Economics, 23: 385-391.

Bun, G. and Kiviet, J. F. (2003): "On the diminishing returns of higher order terms in asymptotic expansions of bias", Economics Letters, 79: $145-152$.
Cainelli, G., Evangelista, R. and Savona, M. (2006): "Innovation and economic performance in services: a firm-level analysis", Cambridge Journal of Economics, 30: 435-458.

Cohen, W. M. and Levin, R. C. (1989): "Empirical studies on innovation and market structure”, In Schmalensee, R. and Willig, R.D. (eds.), Handbook of Industrial Organization (Vol.2, pp. 1060-1107). Amsterdam: North-Holland.

Crepon, B., Duguet, E. and Mairesse, J. (1998): "Research, Innovation, and Productivity: an Econometric Analysis at the Firm Level”, NBER Working Paper Series, No. 6696.

David, P. A., Hall, B. H. and Toole, A. A. (2000): "Is public R\&D a complement or substitute for private $\mathrm{R} \& \mathrm{D}$ ? A review of econometric evidence", Research Policy, 29: 497-529.

Geroski, P. and Walters, C. F. (1995): "Innovative activity over the business cycle", Economic Journal, 105: 916-928.

Hall, B., Mairesse, J., Branstetter, L. and Crepon, B. (1999): "Does cash flow cause investment and R\&D? An exploration using panel data for French, Japanese, and United States scientific firms", in Audretsch, D. and Thurik, R. (eds.) Innovation, Industry Evolution and Employment, Cambridge University Press, Cambridge, pp. 129-156.

Kiviet, J. F. (1995): "On bias, inconsistency, and efficiency of various estimators in dynamic panel data models", Journal of Econometrics, 68: $53-78$. 
Kleinknecht, A. and Verspagen, B. (1990): "Demand and innovation: Schmookler re-examined”, Research Policy, 19: 387-394.

Kleinknecht, A., Van Montfort, K. and Brouwer, E. (2002): "The nontrivial choice between innovation indicators", Economics of Innovation and New Technology, 11: 109-121.

Scherer, F. M. (1982): "Demand-pull and technological invention: Schmookler revisited”, Journal of Industrial Economics, 30: 225-237.

Schmookler, J. (1966): "Invention and Economic Growth", Cambridge, MA, Harvard University Press.
Schumpeter, J. (1942): “Capitalism, Socialism and Democracy", New York, Harper Torchbooks.

Piva, M. and Vivarelli, M. (2007): "Is demand-pulled innovation equally important in different groups of firms?", Cambridge Journal of Economics, 31(5): 691-710.

Piva, M. and Vivarelli, M. (2009): "Demand-pulled innovation under liquidity constraints", Applied Economics Letters, 16(3): 289-293. 